13

\title{
О механизме полного внешнего отражения рентгеновских лучей от поверхности поликристаллических твердых тел
}

\author{
(C) В.М. Стожаров, В.П. Пронин \\ Российский государственный педагогический университет им. А.И. Герцена, \\ 191186 Санкт-Петербург, Россия \\ e-mail: qut1111@yandex.ru, thphys@herzen.spb.ru
}

(Поступило в Редакцию 14 марта 2017 г.)

\begin{abstract}
Изучен механизм полного внешнего отражения рентгеновских лучей от поверхности различных поликристаллических металлов. Проведено комплексное исследование рентгенограмм полного внешнего отражения и дифракции рентгеновских лучей для никеля, меди,серебра, платины и висмута. Методом теоретической обработки экспериментальных рентгенограмм вычислены показатели преломления рентгеновских лучей, числа поверхностных кристаллитов, межплоскостные расстояния и другие величины в исследованных поликристаллических металлах. Установлен закон обратной зависимости показателя преломления от межплоскостных расстояний в кристаллитах поликристаллических твердых тел. Исследован механизм полного внешнего отражения рентгеновских лучей от сегнетоэлектрической пленки цирконата титаната свинца.
\end{abstract}

DOI: 10.21883/JTF.2017.12.45218.2247

\section{Введение}

Метод, основанный на зависимости коэффициента полного внешнего отражения (ПВО) рентгеновских лучей от микрошероховатости поверхности твердого тела, является простым и экспрессным методом для выбора материала элементов зеркальной рентгеновской оптики [1]. Поверхностный характер ПВО рентгеновских лучей позволяет изучать пористые материалы, в частности, измерять степень их пористости [2]. Безлинзовое рентгеновское когерентное изображение поверхности материала, использующее ПВО рентгеновских лучей, широко применяется в настоящее время в определении структур поверхности в наноэлектронике и фотонике [3]. Явление ПВО рентгеновских лучей используется непосредственно в таких элементах рентгеновской оптики, как планарные и параболические многослойные тонкопленочные структуры [4], а также и в капиллярной оптике, способной поворачивать рентгеновские пучки [5]. В связи с широким применением ПВО в технике представляется актуальным исследование механизма ПВО рентгеновских лучей от поверхности поликристаллических твердых тел. В работе [6] предпринято комплексное исследование полного внешнего отражения рентгеновских лучей и установлена обратная зависимость показателя преломления рентгеновских лучей от межплоскостных расстояний в поликристаллическом тантале.

В продолжение работы [6] в настоящей работе проводится изучение зависимости показателя преломления рентгеновских лучей от межплоскостных расстояний в различных поликристаллических металлах, рентгенограммы ПВО рентгеновских лучей которых характеризуется двумя максимумами, соответствующими двум разным показателям преломления $n$. Что касается тех металлов, рентгенограммы ПВО рентгеновских лучей которых характеризуются одним значением показателя преломления, то их нельзя сравнивать между собой, поскольку значение $n$ зависит от порядкового номера элемента $Z$ [7-9]. Кроме того, в настоящей работе изучается механизм полного внешнего отражения рентгеновских лучей от сегнетэлектрической пленки $\mathrm{Pb}\left(\mathrm{Zr}_{0.54} \mathrm{Ti}_{0.46}\right) \mathrm{O}_{3}$, имеющей применение в пьезо и микроэлектронике [10].

\section{Экспериментальные результаты и их обсуждение}

Исследование ПВО рентгеновских лучей от поликристаллических металлов проводилось на стандартной установке ДРОН-7 с использованием эмиссионной линии характеристического спектра рентгеновского излучения $\mathrm{Cu} K_{\alpha_{1}}$ с длиной волны $\lambda=1.5406 \AA$. Методика эксперимента и принципы теоретической обработки кривых отражения от поверхности твердых тел описаны в работе [6]. Показатели преломления $n$ рентгеновских лучей совместно с расчетами плотности рассеивающих атомов $N_{v}$ и величины зоны выхода $x$ рентгеновских лучей, испытавших ПВО, получены для никеля, меди, серебра, платины и висмута. На рис. 1 в качестве примера приведены рентгенограммы для ПВО рентгеновских лучей от серебра и платины. В табл. 1 для всех исследованных металлов в результате обработки рентгенограмм ПВО приведены углы скольжения $\alpha$, отсчитываемые от поверхности образца, показатели преломления $n$ рентгеновских лучей, декременты показателей преломления $\delta=1-n$, а также рассчитанные величины $N_{v}$ и $x$.

Приведенные в табл. 1 параметры ПВО рентгеновских лучей, рассчитанные для всех исследованных металлов, качественно показывают обратную зависимость показателя преломления $n$ рентгеновских лучей от объемной 


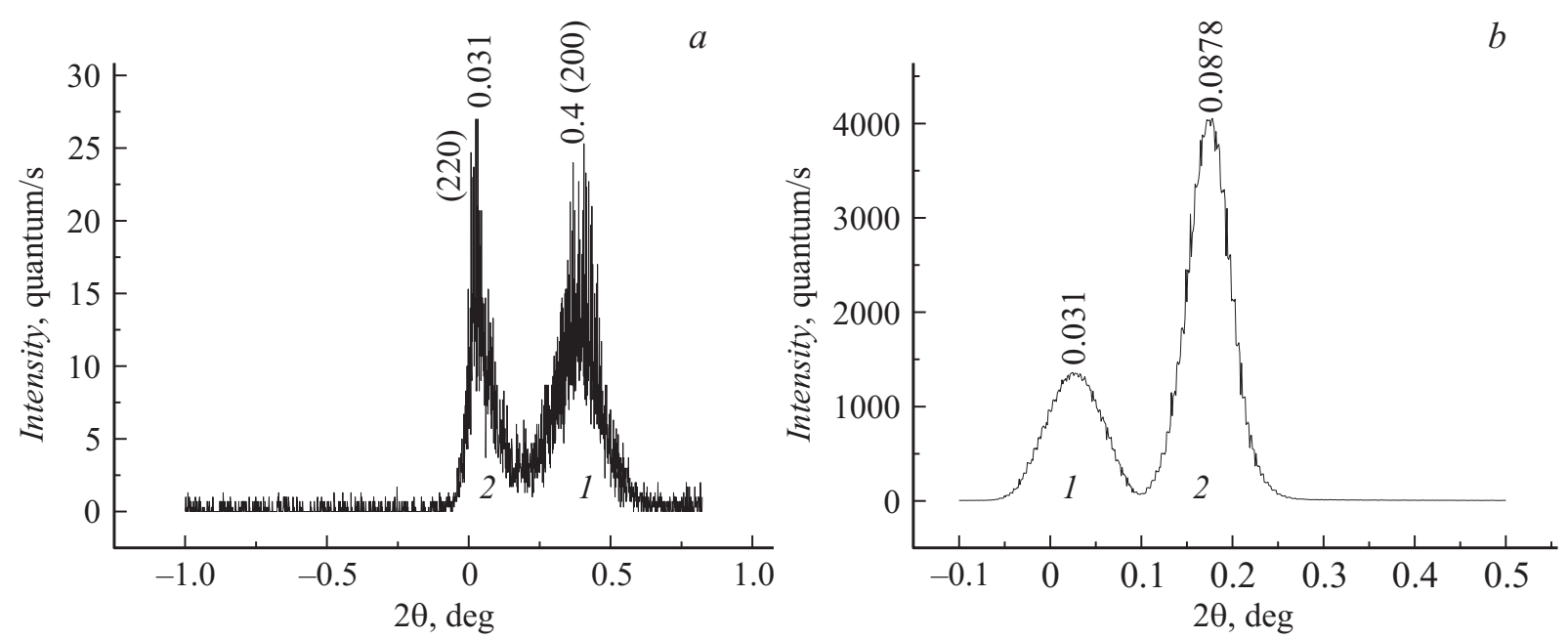

Рис. 1. Рентгенограммы полного внешнего отражения рентгеновских лучей с указанием углов скольжения $\alpha$ в градусах: $a-$ серебро, $b$ - платина.
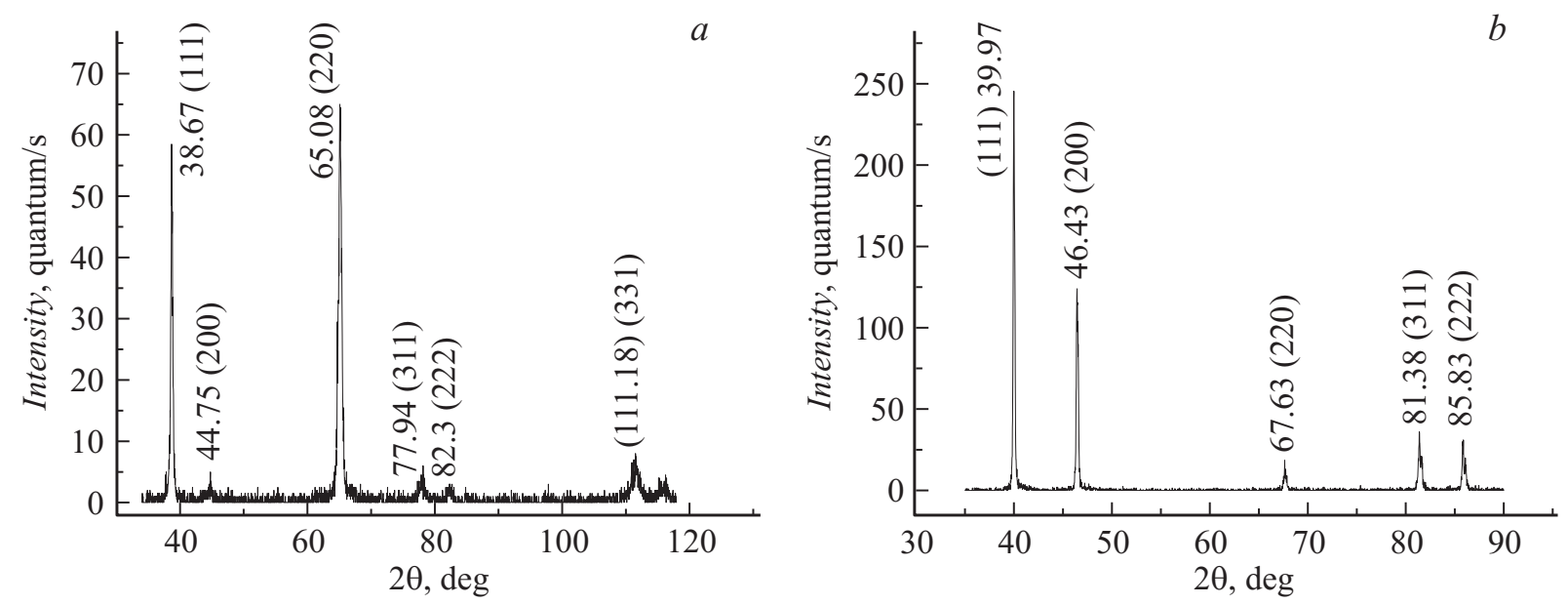

Рис. 2. Дифрактограммы с указанием брэгговских углов рассеяния $2 \theta$ рентгеновских лучей в градусах и индексов Миллера кристаллографических плоскостей: $a-$ серебро, $b-$ платина.
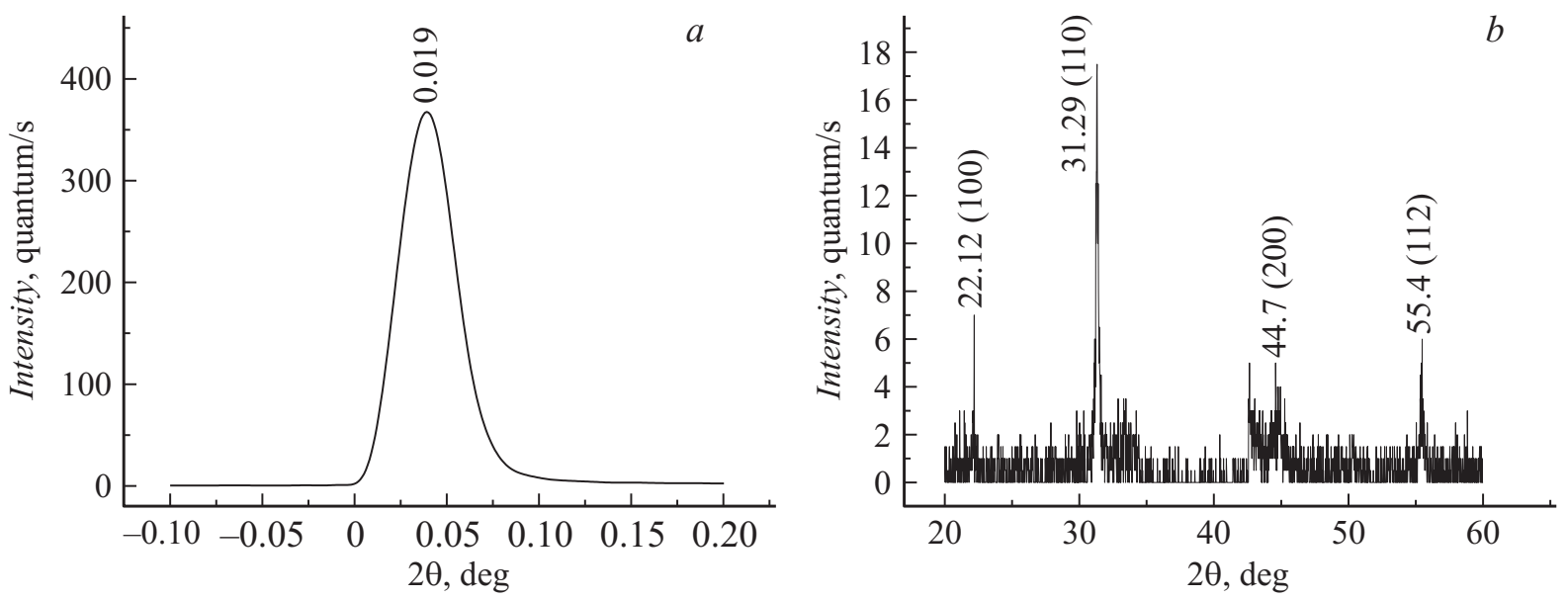

Рис. 3. Рентгенограмма ПВО $(a)$ и дифрактограмма $(b)$ для сегнетоэлектрической пленки цирконата титаната свинца состава $\mathrm{Pb}\left(\mathrm{Zr}_{0.54} \mathrm{TiO}_{0.46}\right) \mathrm{O}_{3}$. 
Таблица 1. Параметры ПВО рентгеновских лучей

\begin{tabular}{|c|c|c|c|}
\hline Металл & Величина & Пик 1 & Пик 2 \\
\hline \multirow{5}{*}{$\begin{array}{l}\text { Никель } \\
Z=28\end{array}$} & $\alpha, \operatorname{deg}$ & 0.00825 & 0.07095 \\
\hline & $n$ & 0.9999999896 & 0.999999233 \\
\hline & $\delta$ & $1.04 \cdot 10^{-8}$ & $7.67 \cdot 10^{-7}$ \\
\hline & $N_{v}$, at $/ \mathrm{mm}^{3}$ & $3.137 \cdot 10^{26}$ & $2.314 \cdot 10^{29}$ \\
\hline & $x, \AA$ & 16.87 & 143.45 \\
\hline \multirow{5}{*}{$\begin{array}{c}\text { Медь } \\
Z=29\end{array}$} & $\alpha, \operatorname{deg}$ & 0.01465 & 0.02895 \\
\hline & $n$ & 0.999999967 & 0.99999987 \\
\hline & $\delta$ & $3.269 \cdot 10^{-8}$ & $1.277 \cdot 10^{-7}$ \\
\hline & $N_{v}$, at $/ \mathrm{mm}^{3}$ & $1.0569 \cdot 10^{23}$ & $3.7159 \cdot 10^{24}$ \\
\hline & $x, \AA$ & 26.57 & 52.5 \\
\hline \multirow{5}{*}{$\begin{array}{c}\text { Серебро } \\
Z=47\end{array}$} & $\alpha, \operatorname{deg}$ & 0.0158 & 0.1884 \\
\hline & $n$ & 0.999999962 & 0.999994594 \\
\hline & $\delta$ & $6.2 \cdot 10^{-8}$ & $5.41 \cdot 10^{-6}$ \\
\hline & $N_{v}$, at $/ \mathrm{mm}^{3}$ & $1.114 \cdot 10^{27}$ & $9.72 \cdot 10^{28}$ \\
\hline & $x, \AA$ & 6.053 & 72.175 \\
\hline \multirow{5}{*}{$\begin{array}{c}\text { Платина } \\
Z=78\end{array}$} & $\alpha, \operatorname{deg}$ & 0.0131 & 0.0878 \\
\hline & $n$ & 0.999999978 & 0.9999988 \\
\hline & $\delta$ & $2.14 \cdot 10^{-8}$ & $7.41 \cdot 10^{-6}$ \\
\hline & $N_{v}$, at $/ \mathrm{mm}^{3}$ & $2.317 \cdot 10^{27}$ & $8.024 \cdot 10^{28}$ \\
\hline & $x, \AA$ & 2.675 & 17.9 \\
\hline \multirow{5}{*}{$\begin{array}{l}\text { Висмут } \\
Z=83\end{array}$} & $\alpha, \operatorname{deg}$ & 0.01335 & 0.05934 \\
\hline & $n$ & 0.999999973 & 0.99999946 \\
\hline & $\delta$ & $2.7 \cdot 10^{-8}$ & $5.4 \cdot 10^{-7}$ \\
\hline & $N_{v}$, at $/ \mathrm{mm}^{3}$ & $2.7475 \cdot 10^{23}$ & $5.495 \cdot 10^{24}$ \\
\hline & $x, \AA$ & 2.455 & 10.99 \\
\hline
\end{tabular}

плотности $N_{v}$ рассеивающих атомов в зоне выхода ПВО и прямую зависимость зоны выхода $x$ рентгеновских лучей, испытавших ПВО, от $N_{v}$. Чтобы выяснить причины такого характера зависимостей $n$ и $x$ от $N_{v}$, необходимо рентгенограммы ПВО рентгеновских лучей сравнить с дифратограммами тех же металлов в широком интервале углов рассеяния $2 \theta$ рентгеновских лучей. На рис. 2 в качестве примера приведены такие дифрактограммы для серебра и платины. Рассчитанные из дифрактограмм числа поверхностных кристаллитов $N_{k r s}$, локализованных в зоне выхода $x$ рентгеновских лучей, испытавших ПВО, и межплоскостные расстояния $d$ для кристаллографических плоскостей $h k l$ для всех исследованных металлов приводятся в табл. 2. Там же из рентгенограмм ПВО рентгеновских лучей для каждого
Таблица 2. Сравнение отношения интенсивностей двух максимумов и отношения соответствующего числа поверхностных кристаллитов с указанием типа кристаллической структуры

\begin{tabular}{c|c|c|c}
\hline Металл & $\begin{array}{c}\text { Отноше- } \\
\text { ние интен- } \\
\text { сивностей }\end{array}$ & $\begin{array}{c}\text { Отношение числа } \\
\text { поверхностных } \\
\text { кристаллов }\end{array}$ & $\begin{array}{c}\text { Тип крис- } \\
\text { таллической } \\
\text { структуры }\end{array}$ \\
\hline Никель & $I_{2} / I_{1}=13$ & $N_{k r s 2} / N_{k r s 1}=13$ & Кубическая $F$ \\
\hline Медь & $I_{1} / I_{2}=1.5$ & $N_{k r s 1} / N_{k r s 2}=1.7$ & То же \\
\hline Серебро & $I_{1} / I_{2}=1.09$ & $N_{k r s 1} / N_{k r s 2}=1.13$ & $-/ /-/ /-$ \\
\hline Платина & $I_{2} / I_{1}=4.1$ & $N_{k r s 2} / N_{k r s 1}=5.6$ & $-/ /-/ /-$ \\
\hline Висмут & $I_{2} / I_{1}=3.7$ & $N_{k r s 2} / N_{k r s 1}=4.03$ & Ромбоэдральная
\end{tabular}

исследованного металла приведены интенсивности $I$ [quantum/s]. двух максимумов, а также взятые из табл. 1 значения показателей преломления $n$ рентгеновских лучей. Все перечисленные параметры, рассчитанные из дифрактограмм, записываются в табл. 3 только относительно двух максимумов на рентгенограммах ПВО, для которых выполняется соотношение: $\frac{I_{1}}{I_{2}} \approx \frac{N_{k r s 1}}{N_{k r s 2}}$. Поэтому в табл. 2 приводятся эти отношения и сингонии для всех исследованных металлов.

Наблюдавшаяся в поликристаллическом тантале обратная зависимость $n(d)[6]$ в настоящей работе полностью подтверждается исследованиями ряда поликристаллических металлов (табл. 3) и следовательно является общим законом для поликристаллических твердых тел. Для физического объяснения этой зависимости используем понятие о силе преломления, введенное в работе [6]. Сила преломления, определяемая углом скольжения $\alpha$ рентгеновских лучей, прямо пропорциональна объемной плотности $N_{v}$ рассеивающих атомов в толщине поверхностного слоя, где происходит полное внешнее отражение рентгеновских лучей, и обратно пропорциональна показателю преломления $n$ рентгеновских лучей согласно соотношению $n=\cos \alpha$ (табл. 1). С другой стороны, из кристаллографических соображений в кристаллических телах увеличение межплоскостного расстояния $d$ всегда приводит к увеличению объемной плотности атомов решетки, а следовательно, к уменьшению показателя преломления рентгеновских лучей. Таким образом, обратная зависимость $n(d)$ становится очевидной.

Поскольку исключительные диэлектрические и пьезозлектрические свойства тонких пленок цирконата титаната свинца $\mathrm{Pb}\left(\mathrm{Zr}_{0.54} \mathrm{Ti}_{0.46}\right) \mathrm{O}_{3}$ (PZT) создают основу для разнообразных практических приложений и в первую очередь в пьезотехнике, представляет интерес исследование механизма ПВО в таких пленках. Объектом исследования в настоящей работе является пленка PZT толщиной $0.3 \mu \mathrm{m}$ на кремниевой подложке с платиновым электродом, полученная методом высокочастотного магнетронного распыления. На рис. 3 представлена рент- 
Таблица 3. Дифракционные данные

\begin{tabular}{|c|c|c|c|}
\hline Металл & Величина & Пик 1 & Пик 2 \\
\hline \multirow{5}{*}{$\begin{array}{l}\text { Никель } \\
Z=28\end{array}$} & $I$, quantum/s & 329.5 & 4275.4 \\
\hline & $N_{k r s} \cdot 10^{9}$ & 19.8893 & 258.4775 \\
\hline & $h k l$ & $(311)$ & $(200)$ \\
\hline & $n$ & 0.9999999896 & 0.999999233 \\
\hline & $d, \AA$ & 1.0611 & 1.7542 \\
\hline \multirow{5}{*}{$\begin{array}{c}\text { Медь } \\
Z=29\end{array}$} & $I$, quantum/s & 759.2 & 507.1 \\
\hline & $N_{k r s} \cdot 10^{9}$ & 42.5812 & 24.4793 \\
\hline & $h k l$ & $(222)$ & $(220)$ \\
\hline & $n$ & 0.999999967 & 0.99999987 \\
\hline & $d, \AA$ & 1.0443 & 1.2786 \\
\hline \multirow{5}{*}{$\begin{array}{c}\text { Серебро } \\
Z=47\end{array}$} & $I$, quantum/s & 13.67 & 12.5 \\
\hline & $N_{k r s} \cdot 10^{9}$ & 56.1798 & 49.5558 \\
\hline & $h k l$ & $(220)$ & $(200)$ \\
\hline & $n$ & 0.999999962 & 0.999994594 \\
\hline & $d, \AA$ & 1.4320 & 2.0234 \\
\hline \multirow{5}{*}{$\begin{array}{c}\text { Платина } \\
Z=78\end{array}$} & $I$, quantum $/ \mathrm{s}$ & 912 & 3765.6 \\
\hline & $N_{k r s} \cdot 10^{9}$ & 46.4268 & 261.583 \\
\hline & $h k l$ & $(200)$ & $(111)$ \\
\hline & $n$ & 0.999999978 & 0.9999988 \\
\hline & $d, \AA$ & 1.9541 & 2.2537 \\
\hline \multirow{5}{*}{$\begin{array}{l}\text { Висмут } \\
Z=83\end{array}$} & $I$, quantum $/ \mathrm{s}$ & 550.5 & 2035.5 \\
\hline & $N_{k r s} \cdot 10^{9}$ & 616.395 & 2489.896 \\
\hline & $h k l$ & $(009)$ & $(003)$ \\
\hline & $n$ & 0.999999973 & 0.99999946 \\
\hline & $d, \AA$ & 1.3180 & 3.9482 \\
\hline
\end{tabular}

генограмма ПВО рентгеновских лучей исследованной пленки PZT и соответствующая дифрактограмма этой пленки. На рентгенограмме ПВО (рис. 3, a) наблюдается один максимум при угле скольжения $\alpha=0.019^{\circ}$ первичного пучка рентгеновских лучей. Используя принципы теоретической обработки кривых отражения от поверхности твердых тел, описанные в работе [6], вычислялись числа поверхностных кристаллитов $N_{k r s}$ в зоне выхода рентгеновских лучей, испытавших ПВО. Оказалось, что те кристаллиты, кристаллографическая плоскость (110) которых параллельна поверхности образца, наиболее многочисленны и в несколько раз превосходят числа кристаллитов для других кристаллических плоскостей (табл. 4).

Из известного угла скольжения $\alpha=0.019^{\circ}$ можно определить ряд характеристик поверхности твер-
Таблица 4. Сопоставление чисел поверхностных кристаллитов $N_{k r s}$ с индексами Миллера $h k l$ кристаллографических плоскостей в пленке РZT

\begin{tabular}{c|c|c|c|c}
\hline$N_{k r s} \cdot 10^{9}$ & 1.52 & 7.11 & 2.2 & 2.0 \\
\hline$h k l$ & 100 & 110 & 200 & 11
\end{tabular}

дого тела. Глубина выхода $x$ рентгеновских лучей, испытавших полное внешнее отражение от пленки PZT, рассчитывается из простого соотношения $x=$ $=R / 2 \sin \alpha$, где $R=2.27 \mu \mathrm{m}$ - практический пробег кванта рентгеновского излучения в пленке $\mathrm{PZT}$, и составляет $x=3.76 \AA$. В таком поверхностном слое PZT вычисляются: показатель преломления рентгеновских лучей $n=\cos \alpha=0.999999945$, декремент показателя преломления, равный $\delta=1-n=5.5 \cdot 10^{-8}$, и объемная плотность рассеивающих атомов $N_{v}$ в зоне выхода ПВО, которая рассчитывается из декремента показателя преломления по формуле: $N_{V}=$ $=\frac{\delta}{0.01184 \cdot 10^{-43} Z}=3.37 \cdot 10^{26} \mathrm{at} / \mathrm{mm}^{3}$. Таким образом, учитывая сравнение числа поверхностных кристаллитов с индексами Миллера пленки PZT (табл. 4), можно утверждать, что полное внешнее отражение от этой пленки происходит от кристаллографической плоскости (110) в пределах тонкого поверхностного слоя $3.76 \AA$ с атомной плотностью $3.37 \cdot 10^{26} \mathrm{at} / \mathrm{mm}^{3}$.

\section{Заключение}

Исследование ПВО рентгеновских лучей от поликристаллических металлов, а также от сегнетоэлектрической пленки цирконата титаната свинца путем одновременного измерения рентгенограмм ПВО и дифракции рентгеновских лучей для каждого исследованного материала, позволяет выяснить основные черты механизма ПВО рентгеновских лучей от твердых тел. Полное внешнее отражение рентгеновских лучей происходит от тех кристаллографических плоскостей кристаллитов, которые параллельны поверхности образца, и в случае двух максимумов на рентгенограммах ПВО от металлов удовлетворяют прямой зависимости интенсивности $i$ го максимума на рентгенограмме ПВО от числа соответствующих поверхностных кристаллитов $N_{k r s i}$ в зоне выхода рентгеновских лучей, испытавших ПВО (табл. 3 и 4). Причем межплоскостные расстояния $d$ в этих кристаллографических плоскостях удовлетворяют обратной зависимости от показателя преломления рентгеновских лучей, т. е. кристаллографические плоскости с меньшими $d$ обладают относительно рентгеновских лучей большей преломляющей способностью и поэтому глубина выхода $x$ рентгеновских лучей, испытавших ПВО, должна быть меньше, что и подтверждает эксперимент (табл. 1) для случая двух разных показателей преломления в исследованных металлах. Что же касается исследования ПВО 
рентгеновских лучей от сегнетоэлектрической пленки $\mathrm{Pb}\left(\mathrm{Zr}_{0.54} \mathrm{Ti}_{0.46}\right) \mathrm{O}_{3}$, то оно показало, что рентгенограмма ПВО от этой пленки характеризуется только одним максимумом и поэтому в этом случае ПВО рентгеновских лучей происходит от одной кристаллографической плоскости (110). В дальнейшем предполагается систематическое исследование пленок PZT с различным содержанием компонентов, кристаллизованных при различных температурах в районе морфотропной границы фазовых переходов второго рода, с целью выявления закономерностей ПВО тонких пленок РZT.

Работа выполнена при частичной финансовой поддержке в рамках проектной части государственного задания. Проект № 16.2811.2017/(ПЧ).

\section{Список литературы}

[1] Якимчук И.В. Особенности отражения рентгеновского излучения от изогнутых поверхностей. Кандидатская диссертация. 2012. М.: МГУ.

[2] Balagurov L.A., Pavlov V.F., Petrova E.A., Boronina G.P. // Semiconductors. 1997. Vol. 31. N 8. P. 815-818.

[3] Sun T., Zhang Jiang, Strzalka J., Okola L., Wang J. // Nature Photonics. 2012. Vol. 6. P. 586-589.

[4] Богдан Т.В. Основы рентгеновской дифрактометрии. Учебно-методическое пособие. М.: МГУ, 2012.

[5] Sun T., Peng S., Lin Z., Sun W., Ma I., Ding X. // J. Appl. Crystallogr. 2013. Vol. 46. P. 1880-1883.

[6] Стохсаров В.М. // ЖТФ. 2017. Т. 87. Вып. 1. С. 1250-129.

[7] Attwood D., Sakdinavat A. Wave Propagation and Refractive Index $X$-Ray and EUV Wavelengths. 2016. P. 1-155.

[8] Павлинский Г.В. Преломление и отражение рентгеновского излучения. Методическое пособие. Иркутский гос. ун-т. Иркутск, 2003. С. 1-217.

[9] Петухов В.Ю., Гумаров Г.Г. Исследование поверхностных слоев твердых тел методом скользящего рентгеновского пучка. Учебно-методическое пособие. Казанский гос. ун-т. Казань, 2009. С. 1-314.

[10] Gruverman A., Kholkin A. // Report on Progress in Physics. 2006. Vol. 69. P. 2443-2474. 